\title{
Children's Dental anxiety after cavity preparation
}

\author{
Camille Torres Costa Ferreira, ${ }^{1}$ Francielle Ribeiro Alves, ${ }^{1}$ Thuanny Castilho, ${ }^{2}$ Leonardo Santos Antunes, ${ }^{1,2}$ Marlus Roberto Rodrigues Cajazeira, ${ }^{1}$ Lívia \\ Azeredo Alves Antunes ${ }^{1,2}$ \\ 'Department of Specific Formation, School of Dentistry, Fluminense Federal University (UFF), Nova Friburgo, RJ, Brazil \\ ${ }^{2}$ Posgraduate Program in Dentistry, School of Dentistry, Fluminense Federal University (UFF), Niterói, RJ, Brazil \\ - Conflicts of interest: none declared.
}

\section{Abstract}

Objective: the purpose of this series of case reports was to evaluate the anxiety in pediatric patients submitted to two mechanical techniques of cavity preparation: the conventional rotary instruments (i.e. high and low speed) using diamond tips, and the ultrasonic abrasion using CVD ${ }^{\mathrm{TM}}$ system tips. Material and Methods: four patients, aged 06-09 years, which had at least two deciduous molars with caries occlusal surface were selected for this study. The teeth were randomly divided into two experimental groups CVD (CVD system with cavity preparation) and CRI group (cavity preparation with rotary instruments). The preparation procedures were performed under a local anesthesia and rubber dam and cavities were restored with composite resin. At the beginning and end of each visit, a closed questionnaire that aimed to assess the child's anxiety during the visit, in which each preparation technique was used, was applied. The results were submitted to descriptive statistical analysis. Results: the patients included were three females and one male. The behavior and anxiety were evaluated in 04 teeth of each group (two from each child). The moderate/severe anxiety was observed for all patients regardless of the technique used for caries removal. Regardless of the tested intervention in most cases children treated had become anxious before the appointments. Conclusion: considering the limitations of this preliminary study, it could be observed that the dental treatment and its related events, regardless the mechanical techniques of cavity preparation used, may be related to anxiety of the pediatric patient.

Keywords: Dental caries; Dental cavity preparation; Dental high-speed technique.

\section{Introduction}

$\mathrm{T}$ he children's behavior is still a barrier in pediatric dentistry, and its control is a key element for successful treatment. ${ }^{1}$ Childhood anxiety related to dental treatment has previously been described in the literature..$^{2-4}$ The degree of cooperation and acceptance of children during the caries removal procedure has a direct influence on clinical performance and treatment success. ${ }^{4}$

The possibility of a minimal cut of the dental tissues and, consequently, less aggression to dental pulp is called minimally invasive techniques and are recognized by providing greater patient comfort during cavity preparation, which is an advantage especially for children. The use of rotary instruments (i.e. high and low speed) can be unpleasant and painful. ${ }^{3,5,6}$

The ultrasonic abrasion technique is primarily accomplished using $\mathrm{CVD}^{\mathrm{ix}}$ system (chemical vapor deposition) produced through chemical bonding of the diamond fragments of metal tips that, in turn, are adapted to a dental ultrasonic device. The wear of the enamel and the dentin is achieved through oscillation of these tips which allows a more accurate and conservative cut of these tissues. ${ }^{3,5} \mathrm{Be}$ sides this important advantage from the biological point of view, since it prevents unnecessary cut of sound enamel and dentin, the ultrasonic abrasion is considered beneficial to produce less noise, does not require significant pressure to the tool and for producing a lower vibration and heat in addition to allowing local anesthesia without treatment and with only relative isolation of use, and well accepted by patients, highlighting as well as aspect of great relevance in pediatric dentistry, for cavity preparation. . $^{3,5-7}$

Based on this, we aimed to evaluate the dental anxiety in pediatric patients submitted to two mechanical techniques of cavity preparation: the conventional rotary instruments (i.e. high and low speed) using diamond tips and the ultrasonic abrasion using $\mathrm{CVD}^{\mathrm{Tm}}$ system.

\section{Ethical Aspects}

\section{Material and Methods}

The present cases report was approved by the local Ethics Committee (No. 565.826). Informed consent was obtained from the children and their parents.

\section{Sample}

Patients of both sexes, with 6-9 years old that presented at least one pair of class I caries lesions located at occlusal surfaces of first or second primary molars were selected. Cases related to systemic diseases, pulp involvement or bruxism, were disclosed for this study. We invited 07 patients to participate. One was excluded due to an inappropriate behavior and two due drop out. The final sample consisted in $04 \mathrm{pa}-$ tients that received treatment in 11 primary molars.

\section{Division of Experimental Groups in Operative Techiniques}

The teeth selected for the study were randomly allocated by lottery method into two groups:

CVD group: the carious enamel and dentin were removed with ultrasonic apparatus (CVDentus ${ }^{\mathrm{Tw}}$, São Paulo, Brazil) using spheric R1n CVD ${ }^{\mathrm{TM}}$ diamond tips (1.0 mm diameter). The tip was installed in the ultrasonic device with the aid of an adapter provided by the manufacturer, and the cut of dental tissues were made with firm buts light movements in order to obtain cutting by oscillation. The ultrasonic device was adjusted at maximum power as recommended by the manufacturer and the water flow was adjusted to enable the cooling of the diamond tip during the removal de carious tissues (Figure 1). 

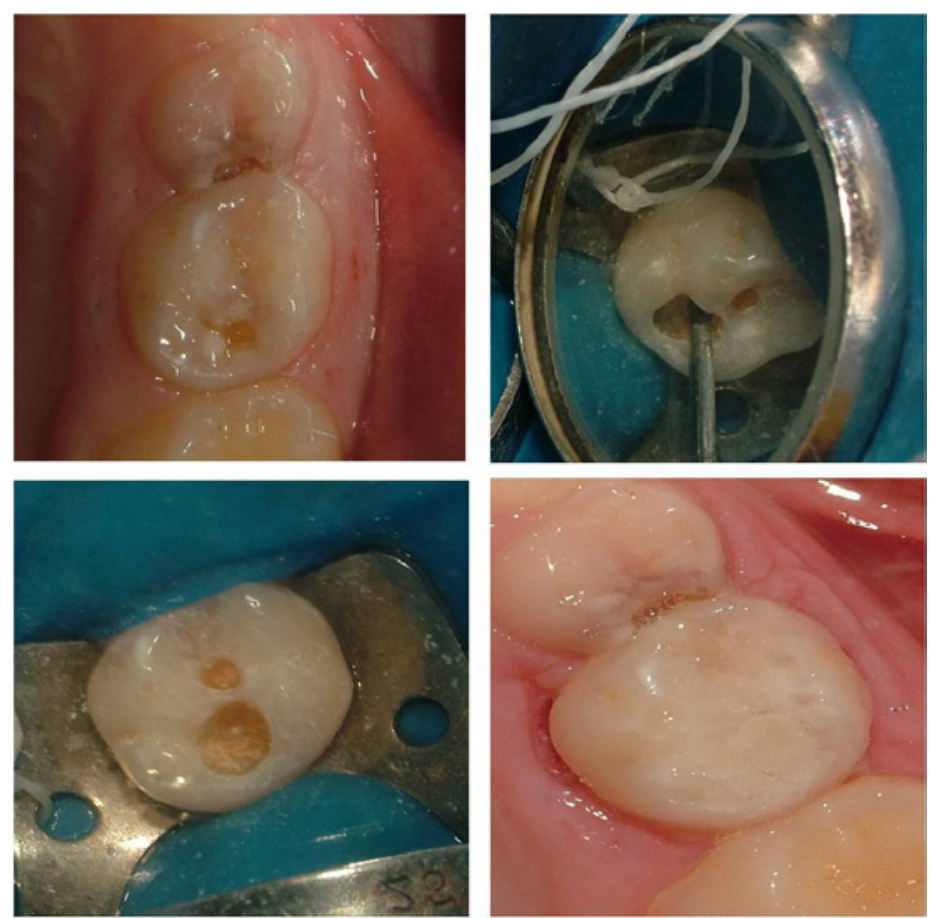

Figure 1. Clinical steps of cavity preparation with CVD ${ }^{\mathrm{TM}}$ tips: A. Aspect of caries lesions; B. Caries removal; C. Final aspect of the cavity surface after removal of carious tissue; D. Composite restoration after removal of rubber dam

CRI group: the undermined enamel was removed with spherical diamond bursno.1011 (KG Sorensen, São Paulo, Brazil) adapted in high speed dental hand piece (Kavo, São Paulo, Brazil) under water cooling. Concluded enamel removal, the infected dentin was removed with no.2 spherical carbide bur (KG Sorensen, São Paulo, Brazil) adapted in a low speed dental hand piece (Kavo, São Paulo, Brazil). Clinical steps are illustrated in Figure 2.
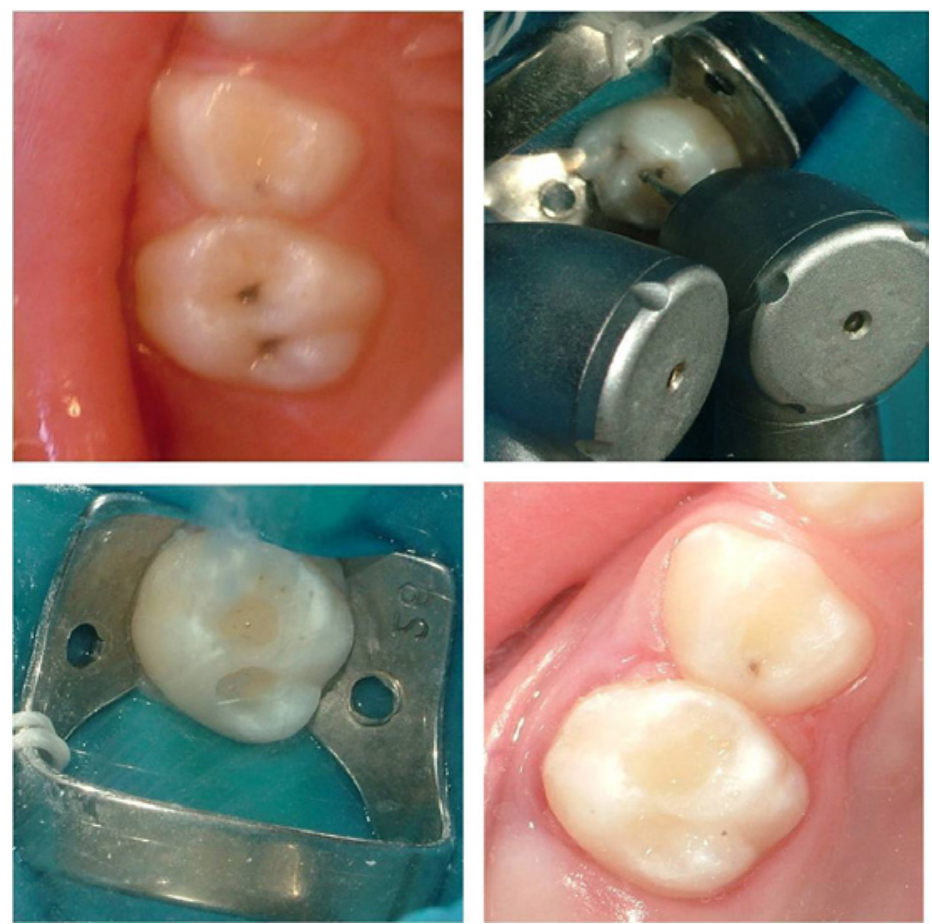

Figure 2. Clinical steps of cavity preparation with high-speed tips: A. Aspect of caries lesions; B. Caries removal; C. Final aspect of the cavity surface after removal of carious tissue; D. Composite restoration after removal of rubber dam

All operatory and restorative procedures were performed after previous local anesthesia (ALPHACAINE ${ }^{\text {rn }}$, DFL, São Paulo, Brazil) and under rubber dam isolation. Considering the MID principles, only undermined enamel and outer layer of carious dentin (i.e. infected dentin) were removed in order to allow the maximum preservation of dental hard tissues. The cavities were restored with Filtek ${ }^{\mathrm{Tm}} \mathrm{Z} 250 \mathrm{com}-$ posite resin (3M ESPE, São Paulo, Brazil) according to manufactures recommendation.

\section{Children's Anxiety Assessment}

A single dentist at the same office treated the children, in order to standardize the service. The technique of "tellshow-do" (TSD) was used with all patients to be reference in the control of behavior and should be used routinely by the professional. ${ }^{1}$ Only during the procedure of local anesthesia the "show" was not performed because it is admittedly an aversive stimulus.

The evaluation of the child's anxiety before and after the dental treatment was measured according scale Frank ${ }^{8}$ that evaluated the acceptance of CRI evaluated systems and CVD by children categorizing their behaviors definitely negative, negative, positive and definitely positive. In addition, we used the Dental Anxiety Scale Corah (DASC) ${ }^{9}$ translated and previously validated for the portuguese language ${ }^{10}$ to measure the dental anxiety levels among children. This scale is based in a questionnaire containing four closed questions (Q), applied by a single operator to assess the anxiety of participants due to certain procedures and dental situations (Q1=If you had to go to the dentist tomorrow, how would you fee 1 about it?; Q2=When you are waiting in the dentist's office for your turn in the chair, how do you feel?; Q3=When you are in the dentist's chair waiting while he gets his drill ready to begin working on your teeth, how do you feel? Q4= You are in the dentist's chair to have your teeth cleaned. While you are waiting and the dentist is getting out the instruments which he will use to scrape your teeth around the gums, how do you feel?). The question was adapted for the second application after the treatment. To help the child in the responses to each item, they were graded in scores that coincide with the visual analog scale. ${ }^{11}$ Response categories of DASC were coded on a five-point scale. The answer option for Q1 was a) I would look forward to it as a reasonably enjoyable experience; b) I wouldn't care one way or the other; c) I would be a little uneasy about it; d) I would be afraid 
that it would be unpleasant and painful; e) I would be very frightened of what the dentist might do. The Q2, Q3 and Q4 presented as option a) Relaxed; b) A little uneasy; c) Tense; d) Anxious; e) So anxious that I sometimes break out in a sweat or almost feel physically sick. Points were assigned for the subject's choices, with one point for an (a) choice to 5 points for an (e) choice. The final value of the DASC questionnaire is obtained by summing from 0 to 20 . The final evaluation of the degree of anxiety was given by the sum of the points scale items: scores less than 4 is considered without anxiety from 5 to 10 low, from 10 to 15 is moderate anxiety, from 15 to 20 serious anxiety bordering on phobia. ${ }^{9}$

The data were tabulated in the SPSS version 17.0, the frequencies were calculated and submitted to descriptive statistical analysis. In the analysis the children those were done two restorations with the same technique it was considered only one.

\section{Results}

The patients included were three females and one male. All children were Caucasian with age ranging from 6 to 8 years. The teeth selected to be included in the study, five were allocated to the CVD group (two primary first molars and three second primary molars) and six for the CRI group (three primary first molars and three second primary molars, Table1).

Behavior and anxiety were evaluated in 04 teeth of each group (two from each child). The moderate/severe anxiety was observed for all patients regardless of the technique used for caries removal (Table 2).
Table 1. Characteristics of the four patients submitted to dental interventions

\begin{tabular}{c|c|c|c|c|c}
\hline \multirow{2}{*}{ Patient } & \multirow{2}{*}{ Gender } & \multirow{2}{*}{ Etigenity } & \multirow{2}{*}{ Age } & \multicolumn{2}{|c}{ Teetht reated } \\
\cline { 4 - 6 } & & & CVD & CRI \\
\hline 1 & F & C & 8 & 54 & 75 \\
\hline 2 & F & C & 6 & $55 / 74$ & $64 / 75$ \\
\hline 3 & F & C & 6 & 55 & 84 \\
\hline 4 & M & C & 7 & 65 & $54 / 55$ \\
\hline
\end{tabular}

Gender: $f$ - female, $m$-male; Ethnicity: c-caucasian, a-afrodescendants

Table 2. Child acceptance by Frankl scale and score /degree of anxiety according to Dental Anxiety Scale Corah

\begin{tabular}{|c|c|c|c|c|c|c|}
\hline \multirow{3}{*}{ Patient } & \multicolumn{3}{|c|}{ CRI Group } & \multicolumn{3}{|c|}{ CVD Group } \\
\hline & \multirow[t]{2}{*}{$\begin{array}{c}\text { Frankl } \\
\text { scale }\end{array}$} & \multicolumn{2}{|c|}{$\begin{array}{c}\text { DASC } \\
\text { questionnaire } \\
\text { Total Score }\end{array}$} & \multirow[t]{2}{*}{$\begin{array}{l}\text { Frankl } \\
\text { scale }\end{array}$} & \multicolumn{2}{|c|}{$\begin{array}{c}\text { DASC } \\
\text { questionnaire } \\
\text { Total Score }\end{array}$} \\
\hline & & before & after & & before & after \\
\hline No.1 & ++ & $\begin{array}{c}15 \\
(\mathrm{MA})\end{array}$ & $\begin{array}{c}15 \\
(\mathrm{MA})\end{array}$ & ++ & 18 (SA) & $\begin{array}{c}17 \\
(\mathrm{SA})\end{array}$ \\
\hline No.2 & - & $\begin{array}{c}19 \\
(\mathrm{SA})\end{array}$ & $16(\mathrm{SA})$ & - & 20 (SA & $\begin{array}{c}15 \\
(\mathrm{MA})\end{array}$ \\
\hline No.3 & - & $\begin{array}{c}19 \\
(\mathrm{SA})\end{array}$ & $21(\mathrm{SA})$ & - & $\begin{array}{c}13 \\
(\mathrm{MA})\end{array}$ & $\begin{array}{c}15 \\
(\mathrm{MA})\end{array}$ \\
\hline No.4 & ++ & $\begin{array}{c}14 \\
(\mathrm{MA})\end{array}$ & 19 (SA) & ++ & $\begin{array}{c}15 \\
(\mathrm{MA})\end{array}$ & $\begin{array}{c}12 \\
(\mathrm{MA})\end{array}$ \\
\hline
\end{tabular}

less than $4=$ without anxiety (WA); from 5 to $10=$ low anxiety (LA); from 11 to $15=$ moderate anxiety (MA); from 16 to $20=$ serious anxiety (SA)

Regardless of the tested intervention in most cases, children treated had become anxious before the appointments that can be evidenced by the high percentage of "D" and "E" options recorded in all questions (Table 3).

Table 3. Frequency of answers given by the children before and after the interventions

\begin{tabular}{|c|c|c|c|c|c|c|c|c|c|c|c|}
\hline \multirow{2}{*}{$\begin{array}{l}\text { Intervention } \\
\text { Group }\end{array}$} & \multirow{2}{*}{$\begin{array}{r}\text { Questions } \\
\text { Answer } \\
\text { option }\end{array}$} & \multicolumn{2}{|c|}{ Question 1} & \multicolumn{2}{|c|}{ Question 2} & \multicolumn{2}{|c|}{ Question 3} & \multicolumn{2}{|c|}{ Question 4} & \multirow{2}{*}{$\begin{array}{l}\text { Total } \\
\text { Before }\end{array}$} & \multirow{2}{*}{$\begin{array}{l}\text { Total } \\
\text { After }\end{array}$} \\
\hline & & Before(\%) & After(\%) & Before(\%) & After(\%) & Before(\%) & $\begin{array}{c}\text { After } \\
(\%)\end{array}$ & $\begin{array}{c}\text { Before } \\
(\%)\end{array}$ & $\begin{array}{c}\text { After } \\
(\%)\end{array}$ & & \\
\hline \multirow{6}{*}{$\begin{array}{l}\frac{0}{3} \\
\frac{0}{\sigma o} \\
\bar{x}\end{array}$} & A & 0 & 0 & 0 & 0 & $1(25.0)$ & 0 & 0 & 0 & $1(6.3)$ & 0 \\
\hline & B & 0 & $1(25.0)$ & 0 & 0 & 0 & 0 & $1(25.0)$ & 0 & $1(6.3)$ & $1(6.3)$ \\
\hline & C & 0 & 0 & $1(25.0)$ & 0 & 0 & $1(25.0)$ & 0 & 0 & $1(6.3)$ & $1(6.3)$ \\
\hline & D & 0 & $1(25.0)$ & $1(25.0)$ & $1(25.0)$ & $2(50.0)$ & $3(75.0)$ & $1(25.0)$ & $1(25.0)$ & $4(25.0)$ & $6(37.4)$ \\
\hline & E & $4(100)$ & $2(50.0)$ & $2(50.0)$ & $3(75.0)$ & $1(25.0)$ & 0 & $2(50.0)$ & $3(75.0)$ & $9(56.1)$ & $8(50.0)$ \\
\hline & Total & $4(100)$ & $4(100)$ & $4(100)$ & $4(100)$ & $4(100)$ & $4(100)$ & $4(100)$ & $4(100)$ & $16(100)$ & $16(100)$ \\
\hline \multirow{6}{*}{$\begin{array}{l}\frac{0}{3} \\
0 \\
0 \\
0 \\
0\end{array}$} & A & 0 & $1(25.0)$ & 0 & 0 & 0 & 0 & $1(25.0)$ & $1(25.0)$ & $1(6.3)$ & $2(12.6)$ \\
\hline & B & 0 & 0 & $1(25.0)$ & $1(25.0)$ & 0 & 0 & 0 & $1(25.0)$ & $1(6.3)$ & $2(12.6)$ \\
\hline & C & 0 & 0 & 0 & 0 & $1(25.0)$ & 0 & 0 & 0 & $1(6.3)$ & 0 \\
\hline & D & 0 & $1(25.0)$ & $2(50.0)$ & $2(50.0)$ & $1(25.0)$ & $3(75.0)$ & $2(50.0)$ & $1(25.0)$ & $5(31.1)$ & $7(43.7)$ \\
\hline & E & $4(100)$ & $2(50.0)$ & $1(25.0)$ & $1(25.0)$ & $2(50.0)$ & $1(25.0)$ & $1(25.0)$ & $1(25.0)$ & $8(50.0)$ & $5(31.1)$ \\
\hline & Total & $4(100)$ & $4(100)$ & $4(100)$ & $4(100)$ & $4(100)$ & $4(100)$ & $4(100)$ & $4(100)$ & $16(100)$ & $16(100)$ \\
\hline
\end{tabular}




\section{Discussion}

Carious lesions that affect dentin are treated by restorative treatment in most of the cases. In addition, to contribute to the recovery of tooth function and esthetics, the placement of dental restorations is important because they eliminate retention sites of cariogenic biofilm. ${ }^{13}$

In the present study, restorations were performed on the occlusal surfaces, recognized as sites vulnerable to dental caries because of their anatomy. ${ }^{11}$ This becomes even more problematic in deciduous teeth where the lesion progresses faster due to the higher solubility of enamel and deciduous dentin to bacterial acids. ${ }^{14-16}$

Thus, it is essential to implement the philosophy of minimal intervention in the pediatric dental clinic that prioritizes risk identification, early diagnosis of lesions and performing restorative practices that preserve the most of the dental structure. However, nowadays, dental treatment persists as a source of anxiety and fear for most of pediatric patients, particularly when restorative procedures are necessary.

The effects of the dental treatment on the level of anxiety were observed in this study through the items Q1 and Q2 of the questionnaire. As seen in Q1 item, the possibility of the child visit the dentist generates worry. The same level of worry persisted in the waiting room (Q2 item). The fact that the dental treatment affects patient anxiety levels are often reported in the literature. ${ }^{17-21}$

The majority of professional uses rotary instruments for the removal of enamel and dentine compromised by caries. These instruments have the advantage of versatility of its clinical application, convenience, speed and effectiveness in the removal of decayed tissue. ${ }^{6}$

However, research has suggested that these instruments can cut healthy mineralized tissues. The excessive removal of the dental tissues during cavity preparation is in disagreement with the dental minimal intervention which advocates the selective removal of carious dentin to its outer layer called infected dentin. ${ }^{22,23}$ In addition, the friction of the dental drills with the surface of enamel and dentin generates heat and pressure which represents a risk to the integrity of the pulp tissue. ${ }^{5}$

In view of the problems associated with the use of rotary instruments, alternative methods for performing the cavity preparation have been proposed. In this study, the ultrasonic abrasion using $\mathrm{CVD}^{\mathrm{rx}}$ system was evaluated. This method is based on the use of diamond coated metallic tips that are adapted to a ultrasonic device that promote the cut of the dental hard tissues by oscillation motion. ${ }^{24}$

$\mathrm{CVD}^{\text {is }}$ tips were produced at the National Institute of Spatial Research (INPE) in Brazil for use in dentistry. Through a chemical process, this metallic tips are coated by diamond after a chemical vapor deposition process (chemical vapor deposition, CVD), forming a diamond film on the surface of a molybdenum rod, thus providing a diamond continuous layer completely closed and adherent to the metal. ${ }^{25-27}$

The diamond tips used in $\mathrm{CVD}^{\mathrm{in}}$ system are angled that facilitates the access to the interior of cavitated lesions in dentin addition to allowing visibility of the operatory site avoiding unnecessary removal of sound dentin. In the same way, ultrasonic vibration reduces the contact time of the diamond tip with dental surfaces which contributes to reducing the pain and discomfort during caries removal and improves patient acceptance. ${ }^{26}$

Under the perspective of minimal intervention dentistry, ultrasonic abrasion results in conservative removal of hard tissue, but in some cases there is a tendency of insufficient removal of the infected dentin. ${ }^{28}$

The use of $\mathrm{CVD}^{\mathrm{ix}}$ system have been proposed with success in several areas such as endodontics, implant dentistry and, pediatric dentistry. But the most interesting application, which offers the best advantages, is its successful use in minimally invasive dentistry. This new cavity preparation method allows preservation of sound tooth tissues and offers a promising perspective in dentistry with regard to conservative cavity preparation. ${ }^{26}$ Another important aspect related to $\mathrm{CVD}^{\mathrm{rn}}$ system is that noise, pain and discomfort produced, factors considered as the main responsible for the fear and anxiety associated with dental treatment are lower than those produced by the rotary instruments. ${ }^{29}$

As noted in this study, based on responses provided to Q3 and Q4 items of the questionnaire, there were no differences observed in the responses to the standards of worry when the rotary instruments and $\mathrm{CVD}^{\mathrm{m}}$ system were used. However, it must be considered that the reduced number of patients in the sample is a limitation of this study and prevents the extrapolation of results to the pediatric population. Similarly, it should be taken into account a possible limitation of the child to establish what is your own threshold of pain/discomfort. That is to say, exemplifying Q3 questionnaire item, regardless of the method used, depending on the child's anxiety, the response patterns may be similar.

Another important factor that must be addressed is the concern of pediatric patients regarding local anesthesia. Almost in all cases, the children proved to be "very anxious" or "extremely anxious". The relationship between local anesthesia and childhood anxiety is already known in the dental treatment. ${ }^{19}$ Because of local anesthesia have preceded the cavity preparation procedures, it is important to consider its effects on responses to Q3 and Q4 of the questionnaire items. Thus, the patients evaluated at the time of performing cavity preparations, could already have high levels of concern due to the anesthesia, and it probably interfered with your answers provided to these items.

Finally, due to the limited number of patients, the chances of the results of this study regarding to similarity in anxiety 
patterns recorded for the two methods studied cavity preparation, be generalized to the child population are limited. However, the cut characteristics promoted by $\mathrm{CVD}^{\text {rix }}$ system in accordance with the current practice of restorative dentistry based on the minimal invasiveness precepts favor the continuation of this study. In addition, with respect to this aspect, it is necessary that the restorations be longitudinally evaluated in order to allow conclusions about the effects of this method on the longevity of composite resin can be obtained.

\section{Conclusion}

Based on the results obtained of this study it could be observed that the dental treatment and its related events, regardless the mechanical techniques of cavity preparation used, may be related to anxiety of the pediatric patient.

\section{Acknowledgment}

This study was supported by grant (E-26/010.002084/2016) from Fundação Carlos Chagas Filho de Amparo à Pesquisa do Estado do Rio de Janeiro (FAPERJ).

\section{References}

1. Dean JA, David RA, Ralph E. McDonald. McDonald and Avery's Dentistry for the Child and Adolescent. Elsevier:10th Edition 2018.720p.

2. Pedro RL, Antunes LA, Antunes LS, Maia, LC. Percepção dos responsáveis sobre fatores prediletores do medo odontológico infantil e aceitação do uso da abrasão a ar como nova tecnologia para remoção de tecido cariado. Rev Flum Odontol. 2012;38(2):3-8.

3. Lopes F, Pedro RL, Antunes LA, Pomarico L, Maia LC. Percepção de responsáveis sobre medo odontológico e técnica alternativa para remoção de cárie. Rev Bras Odontol. 2011;68(2):166-70.

4. Klingberg G, Broberg AG. Dental fear/anxiety and dental behaviour management problems in children and adolescents: a review of prevalence and concomitant psychological factors. Int J Paediatr. 2007;17(6):391-406.

5. Pedro RL, Antunes LA, Vieira AS, Maia LC. Analysis of primary and permanent molars prepared with high speed and ultrasonic abrasion systems. J Clin Pediatr Dent. 2007;32(1):49-52.

6. Banerjee A, Watson TF, Kidd EA. Dentine caries excavation: a review of current clinical techniques. Br Dent J. 2000;188(9):476-82.

7. Banerjee A. Minimal intervention dentistry: part 7. Minimally invasive operative caries management: rationale and techniques. Br Dent J. 2013;214(3):107-11.

8. Frankl S, Shiere F, Fogels H. Should the parent remain with the child in the dental operatory? J Dent Child (Chic).1962;29:150-63.

9. Corah NL, Gale EN, Illig SJ. Assessment of a dental anxiety scale. J Am Dent Assoc.1978;97(5):816-9.

10. Hu LW, Gorenstein C, Fuentes D. Portuguese version of Corah's Dental Anxiety Scale: transcultural adaptation and reliability analysis. Depress Anxiety. 2007;24(7):467-71.

11. Nazif M. Thioridazine and secobarbital as premedicating agents. J Dent Child (Chic). 1971;38(3):206-10.

12. Boman UW, Wennström A, Stenman U, Hakeberg M. Oral health-related quality of life, sense of coherence and dental anxiety: An epidemiological cross-sectional study of middle-aged women. BMC Oral Health. 2012;12:14.

13. Fejerskov O, Kidd E. Dental caries - The disease and its clinical management. 2nd ed. 2008. P.355.

14. Sabel N, Robertson A, Nietzsche S, Noren JG. Demineralization of enamel in primary second molars related to properties of the enamel. Scientific World Journal. 2012;2012:587254.
15. Oliveira MAM, Torres CP, Gomes-Silva JM, Chinelatti MA, De Menezes FC, Palma-Dibb RG, et al. Microstructure and mineral composition of dental enamel of permanent and deciduous teeth. Microsc Res Tech. 2010;73(5):572-7.

16. Wang LJ, Tang R, Bonstein T, Bush P, Nancollas GH. Enamel Demineralization in Primary and Permanent Teeth. J Dent Res. 2006;85(4):359-63.

17. Wilson S. Management of Child Patient Behavior: Quality of Care, Fear and Anxiety, and the Child Patient. J Endod. 2013;39(3):573-7.

18. Porritt J, Marshman Z, Rodd H. Understanding children's dental anxiety and psychological approaches to its reduction. Int J Paediatr Dent. 2012;22(6):397-405.

19. Jimeno FG, Bielsa SY, Fernández CC, Rodríguez AIL, Bellido MM. Objective and subjective measures for assessing anxiety in paediatric dental patients. Eur J Paediatr Dent. 2011;12(4):239-44.

20. Klinberg G. Dental anxiety and behaviour management problems in paediatric dentistry--a review of background factors and diagnostics. Eur Arch Paediatr Dent. 2008;9(1):11-5.

21. Smith T, Heaton L. Fear of dental care: are we making any progress? J Am Dent Assoc. 2003;134(8):1101-8.

22. Fusayama T. Two layers of carious dentin; diagnosis and treatment. Oper Dent. 1979;4(2):63-70.

23. Fusayama T. Intratubular crystal deposition and remineralization of carious dentin. J Biol and Buccale. 1991;19(3):255-62.

24. Jingarwar MM, Bajwa NK, Pathak A. Minimal intervention dentistry - a new frontier in clinical dentistry. J Clin Diagn Res. 2014;8(7):ZE04-8.

25. Vieira AS, Santos MP, Antunes LA, Primo LG, Maia LC. Preparation time and sealing effect of cavities prepared by an ultrasonic device and a high-speed diamond rotary cutting system. J Oral Sci. 2007;49:207-11.

26. Antunes LAA, Antunes LS, Maia LC. CVD diamond used in dentistry. Industrial Diamond Review. 2008:14-7.

27. Vasconcellos BT, Thompson JY, Paula Macedo MR, Maia JMO, Oda M, Garone-Netto N. Ultrasonic cavity preparation using CVD coated diamond bur: A case report. Eur J Dent. 2013;7(1):127-32.

28. Banerjee A, Kidd E, Watson T. In vitro evaluation of five alternative methods of carious dentin excavation. Caries Res. 2000;34(2):144-50.

29. Antônio AG, Primo LG, Maia LC. Case report: ultrasonic cavity preparation - an alternative approach for caries removal in paediatric dentistry. Eur J Paediatr Dent. 2005;61:105-8

\section{Mini Curriculum and Author's Contribution}

1. Camille Torres Costa Ferreira - DDS. Contribution: first and the final draft of the manuscript, data collection and writing of the manuscript.

2. Francielle Ribeiro Alves - DDS. Contribution: first and the final draft of the manuscript, data collection and writing of the manuscript.

3. Thuanny Castilho - DDS and MSc. Contribution: first and the final draft of the manuscript and writing of the manuscript.

4. Leonardo Santos Antunes - DDS and PhD. Contribution: designed the case report, reviewed critically the final draft of the paper.

5. Marlus Roberto Rodrigues Cajazeira - DDS and PhD. Contribution: designed the case report, data collection and reviewed critically the final draft of the paper.

6. Lívia Azeredo Alves Antunes - DDS and PhD. Contribution: first and the final draft of the manuscript, designed the case report, data collection and reviewed critically the final draft of the paper.

Submitted: 02/20/2018 / Accepted for publication: 03/15/2018

\section{Corresponding Author}

Lívia Azeredo Alves Antunes

E-mail: liviaazeredo@gmail.com 